\title{
Review Article on Transoral Endoscopic Thyroid Surgery
}

\author{
Dipankar Saha* \\ Consultant Laparoscopic Surgeon, Desun Hospital, India
}

Submission: February 10, 2017; Published: February 27, 2017

*Corresponding author: Dipankar Saha, Consultant Laparoscopic Surgeon,Desun Hospital, Kolkata, India, Tel: +919821743606; Email: dipankarsaha8888@gmail.com

\section{Introduction}

One of the most commonly performed surgical procedure thyroidectomy has undergone major technological changes owing to constant efforts of surgical community to to never ending demand of better surgical results in regards of safety, cosmesis and functionality along with monitoring of recurrent laryngeal nerve,assays for parathyroid hormone and use of alternative energy sources various procedures using endoscopes have gone sea change as far as minimally invasive surgery for thyroid is concerned though procedures like minimally invasive non endoscopic thyroid surgery exists [1] but endoscopic thyroid surgery is gaining popularity first described by gagner in 1996 for parathyroid surgery [2] several new procedures are present today for thyroid and parathyroid surgeries endoscopically these procedures are reserved for smaller sized nodules of upto $3 \mathrm{~cm}$ in size and offer better ilumination an visualisation of the operative field, less post op pain and faster recovery along with better cosmesis for the patient.

These endoscopic approaches include the minimally-invasive video-assisted thyroidectomy (MIVAT), the endoscopic lateral approach, the lateral mini-incision approach, the anterior/chest (hybrid) approach, the transaxillary approach, the axillo-breast approach, the post-auricular and axillary approach and other novel experimental approaches. Some of these approaches could be done with the assistance of the da Vinci robot (i.e. roboticassisted thyroidectomy). For simplification, these approaches could be categorized into the cervical/direct approach and extra-cervical/indirect approach. Each technique or approach has its own benefits and weaknesses.

\section{Objective of review}

This review aimed to know the outcome of transoral endoscopic thyroid surgery.

\section{Materials and Methods}

This review is prepared by downloading the articles from several search engine like PubMed, Medline, Scopus,
EbscoHost,springer etc. Only articles pertaining to and relevant to transoral endoscopic thryroid surgery analysed and used in this study. Variables such as operative time, cosmetic outcome, complications, length of hospital stay, and post-operative pain were evaluated.

\section{Results}

Transoral Thyroid surgery is a relatively new approach which has been reported in a few articles only till date one of the first of these was done in human cadaver and pigs [3] primarily to reduce scar and reduce distance of tissue dissection distance K.witzel et al. [3] in germany used human cadavers and pigs in order to define the procedure after being motivated by earlier reports of removal of ectopic thyrpoid tissue by oral route $[4,5]$ they deduced that this is a safe and rapid approach without injury to nerve or major bleeding.also neuromonitoring was added by them in some experiments [6]. Little later Jeremy D.richmon et al. [7] published an article on robot assisted transoral thyroidectomy on a cadaver for a preclinical cadaver feasibility study [7] where they outlined the possible difficulties associated with the procedure, this study and another study done by lee j et al. [8] indicated that this route can give a better access to recurrent laryngeal nerve than lateral approaches and hence will have a diminished learning curve ,also these two studies warned about the challange of creating submandibular pocket during the surgery. Anuwong a. Published a report on first 60 patients operated during 2014-2015 using transoral endoscopic thyroidectomy vestibular approach (TOETVA) [9].

\section{Results}

A series of 60 procedures were accomplished successfully. 42 patients had single-thyroid nodules, and a lobectomy was performed. 22 patients had multinodular goiters and two patients had Graves' disease, with total thyroidectomy or Hartley-Dunhill procedures performed. Two had papillary thyroid carcinoma, and total thyroidectomy with central node dissection was performed. The median operative time was 
115.5 min (range 75-300 min). The median blood loss was 30 $\mathrm{mL}$ (range 8-130 $\mathrm{mL}$ ). Two patients experienced a transient hoarseness, which was resolved within 2 months. One patient experienced a late postoperative hematoma, which was treated conservatively. No mental nerve injury or infections were found. The patients were discharged in an average of 3.6 days (range 2-7 days) postoperatively.

Jun-Ook Park et al. [10] Department of Otolaryngology Head and Neck Surgery, Inje University College of Medicine, Busan, Korea recently experienced a case of transoral endoscopic thyroidectomy via the trivestibular approach. They identified and preserved all neighboring critical structures during surgery. The patient was discharged on postoperative day 3. There were no complications in thyroid function, vocal cord function, or lower lip sense. Transoral endoscopic thyroidectomy via a trivestibular approach provides a short and direct route to the thyroid and an adequate workspace without a skin incision.

Gyan chand, Sk mishra at SGPGI lucknow, India [11] published their experience on the procedure, they indicated they faced difficulty during port placement and specimen retrieval due to prominent chin and larger adams apple in Indian patient, they selected more patients with small nodules and longer neck to ward off this problem, patients wer satisfied after surgery and soft diet allowed on first post op day and discharged 2 days after surgery no other untoward incident reported in their study.

Vishwanath M. Pai*, Pari Muthukumar, Apoorva Prathap, Jayanth Leo, Rekha A. Department Of General Surgery, Sri Ramachandra Medical College, Chennai, India ,presented a single case report on surgery done on a 21 yr old female chose to insufflate the field with carbondioxide, thus eliminating the scar produced by the introduction of the Kirschner wires. The following criteria were satisfied:

a) thyroidgland was approached using minimal dissection;

b) patient was left with no visible scar. The procedure took us two hours.

Post-operatively the patient developed mild emphysema, whichresolved spontaneously. This surgicalemphysemawas due to insufflationof the surgical field with carbon dioxide and required nointervention. Although the surgical fieldwasclean, the port of entry,which was the inferior vestibule, is not sterile and hence she wasstarted on oral antibiotics and antiseptic mouthwash to preventwound infection. Oral intake was started on post-op day 1 and shewas discharged within aweek [12]. One month post-operatively,she was comfortable with no complications.

Seung Hoon Woo [13] Department of Otolaryngology and Institute of Health Sciences, Gyeongsang National University, Jinju, Korea reported the case of a 35-year-old woman with a $0.5 \times 0.5-\mathrm{cm}$ papillary thyroid microcarcinoma. implementing a modified approach for the removal of the thyroid by using a frenotomy incision of the mouth, accompanied by an endoscope system. The total operating time was 120 minutes, and there were no specific complications. The patient continues to be free of any diseases 12 months after the excision. LEE et al., in 20142015 ,operated on porcine model,cadavers and live patients for various thyroid disorders like follicular adenoma, papillary carcinoma,nodular hyperplasia ,using oral route and DA vinci robotic system,they did total thyroidectomy,lobectomy and central neck dissection with robots and only had mental nerve stretching and tear as complication, the tear was addressed intaroperatively $[14,15]$.

\section{Discussion}

Transoral approach for thyroid surgery is practiced only by handful people around the world, though the feasibility studies $[3,6,8]$ was done few years back in human and other models and even today the available aricles are few, cosmesis and ease of dissection compared to axillary approach are main appeals for this approach.some authers use insufflations and some do not, recent reports are based on using traditional laparoscopic instruments and ultrasonic energy [9] sources most surgeons are practicing fornodes lesser than $6 \mathrm{~cm}$ complications were negligible and patient satisfaction in terms of cosmesis and pain were very much acceptable robotic surgery is adding new dimension to this surgery.

\section{Conclusion}

Transoral thyroid surgery is a feasaable and safe technique for smaller sized, euthyroid glands, even carcinomas can be operated by this technique, it is still in its early days but has got the merits to become popular owing to the demand of scarless surgery and ease of dissection planes compared to transaxillary approach.

\section{References}

1. Gagner M (1996) Endoscopic subtotal parathyroidectomy in patients with primary hyperthyroidism. Br J Surg 83(6): 875.

2. Park CS, Chung WY, Chang HS (2001) Minimally invasive open thyroidectomy. Surg Today 31(8): 665-669.

3. Witzel K, von Rahden BH, Kaminski C, Stein HJ (2008) Transoral access for endoscopic thyroid resection. Surg Endosc 22(8): 1871-1875.

4. Prisman E, Patsias A, Genden EM (2015) Transoral robotic excision of ectopic lingual thyroid: Case series and literature review. Head Neck 37(8): E88-E91.

5. Jiang XZ, Chen BS, Wang WC, Zhao YF, Wang Y (1993) The diagnosis and the treatment on lingual thyroid. Shanghai Kou Qiang Yi Xue 2(2): 73-76.

6. Witzel K, Benhidjeb T (2009) Monitoring of the recurrent laryngeal nerve in totally endoscopic thyroid surgery. Eur Surg Res 43(2): 72-76.

7. J Robotic Surg (2011) 5: 279-282.

8. Lee J, Yun JH, Nam KH, Soh EY, Chung WY (2011) The learning curve for robotic thyroidectomy: a multicenter study. Ann Surg Oncol 18(1): 226-232. 
9. Anuwong A (2016) Transoral Endoscopic Thyroidectomy Vestibular Approach: A Series of the First 60 Human Cases. World J Surg 40(3): 491-497.

10. Jun-Ook Park, Mi-Ra Kim, Do Hun Kim, Dong Kun Lee (2016) Department of Otolaryngology Head and Neck Surgery, Inje University College of Medicine, Busan, Korea, Ann Surg Treat Res 91(5): 269-272.

11. gyan chand, sk mishra (2016) Tranoral endoscopic thyroid surgery through vestibular approach. world j endoc surgery 8(2): 179-182.

12. Vishwanath M Pai, Pari Muthukumar, Apoorva Prathap, Jayanth Leo, Rekha A (2015) Department of General Surgery, Sri Ramachandra
Medical College, Chennai, India International Journal of Surgery Case Reports 12: 99-101.

13. Woo Seung Hoon (2014) Journal of Laparoendoscopic \& Advanced Surgical Techniques. 24(5): 345-349.

14. Lee HY, Hwang SB, Ahn KM, Lee JB, Bae JW, et al. (2014) The safety of transoralperiosteal thyroidectomy: results of Swine models. J Laparoendosc Adv Surg Tech A 24(5): 312-317.

15. Lee HY, You JY, Woo SU, Son GS, Lee JB, et al. (2015) Transoral periostealthyroidectomy: cadaver to human. Surg Endosc 29(4): 898904.

\section{Your next submission with Juniper Publishers will reach you the below assets}

- Quality Editorial service

- Swift Peer Review

- Reprints availability

- E-prints Service

- Manuscript Podcast for convenient understanding

- Global attainment for your research

- Manuscript accessibility in different formats

( Pdf, E-pub, Full Text, Audio)

- Unceasing customer service

Track the below URL for one-step submission

https://juniperpublishers.com/online-submission.php 